\title{
Kualitas Kepemimpinan Yosua
}

\author{
Petrus Yunianto \\ 1) Dosen Sekolah Tinggi Teologi Tawangmangu \\ *) Penulis korespondensi: petrusyunianto@gmail.com
}

Received: 5 Dec 2018 / Revised: 19 Dec 2018 / Accepted: 26 Dec 2018

\begin{abstract}
Abstrak
Pemimpin tidak dilahirkan, pemimpin dibentuk. Demikianlah ungkapan dari beberapa orang ketika berbicara tentang kepemimpinan. Sekalipun hal tersebut masih menjadi pertentangan, tetapi orang menilai bahwa kelahiran seorang pemimpin merupakan hasil dari proses. Proses menjadi pemimpin menentukan kualitas dari pemimpin tersebut. Seseorang bisa menjadi pemimpin karena pembentukan. Jika ia memiliki keinginan yang kuat, sekalipun ia tidak dilahirkan sebagai seorang pemimpin, ia bisa menjadi seorang pemimpin yang efektif. Pemimpin yang baik mengembangkan dirinya melalui proses tiada henti baik dalam belajar mandiri, pendidikan, pelatihan, dan pengalaman.Kualitas seorang pemimpin terlihat pada saat pemimpin tersebut merespon setiap kejadian yang terjadi dalam hidupnya. Contoh pemimpin yang bisa dipelajari di Perjanjian Lama salah satunya adalah Yosua. Panggilan Yosua sebagai pemimpin Israel tidak terjadi secara instans. Kepemimpinannya teruji dengan waktu dan kesetiaannya ketika mengikuti Musa pemimpinnya. Dikemudian hari, pada saat Yosua menggantikan Musa, disitulah terlihat kualitas dari kepemimpinan Musa. Seperti apakah kualitas dari kepemimpinan Yosua? Pada makalah ini akan dibahas tentang kualitas kepemimpinan Yosua.
\end{abstract}

Kata Kunci: Kepemimpinan, Kualitas, Yosua

\section{Abstract}

The leader is not determined, the leader is formed. Thus the remarks from some people compilation talk about leadership. Even though this is still a 
contradiction, people agree that this is the result of the process. The process of becoming a leader determines the quality of the leader. Being able to be a leader because of formation. If he has a strong desire, he is not supportive as a leader, he can be an effective leader. Leaders who develop themselves through a process that is not good in independent learning, education, training, and experience. Quality of leaders is seen when the leader responds to every event that occurs in the struggle. Examples of leaders that can be learned in the Old Testament are Joshua. Joshua's call as leader of Israel did not happen instantly. His leadership was tested with time and the loyalty of the compilation Moses received was his leadership. Later, when Joshua accepted Moses, there was the quality of Moses' leadership. What is the quality of Joshua's leadership? In this paper we will discuss Joshua's leadership qualities.

Keywords: Leadership, Quality, Joshua

\section{Pendahuluan}

Yosua berasal dari suku Efraim keturunan Yusuf, cucu dari Elisama dan anak dari Nun (1 Taw 7:27; Bil 1:10). Nama Yosua berarti "Yahwe adalah keselamatan", dan nama ini memiliki berbagai bentuk di dalam Alkitab yaitu: Hosea, Yehosua, Osea, Yesus. Nama Yesus merupakan bentuk dalam bahasa Yunani untuk nama ini. ${ }^{1}$ Yosua lahir di Mesir pada masa perbudakan. Sebagai laki-laki Israel, ia bersama saudara-saudaranya diperbudak oleh bangsa Mesir, ia ikut melakukan hal-hal yang diperintahkan oleh para Mandor di Mesir. Meskipun berat kehidupan yang dijalani oleh Yosua muda, namun ia tetap memiliki pengharapan akan pembebasan seperti yang telah dijanjikan oleh Allah kepada bangsa Israel. Keyakinannya akan pengharapan pembebasan ini, membuat Yosua bertumbuh dalam kerohaniannya.

Kepemimpinan Yosua tidak muncul secara tiba-tiba. Proses kehidupan, membuat Yosua bertumbuh sebagai pribadi yang harus siap dalam mengambil keputusan ketika ada permasalahan yang menimpa hidupnya. Keputusan-keputusan yang diambil Yosua pada saat menghadapi tantangan dan permasalahan hidup, menjadikan Yosua kaya akan pengalaman dan juga hikmat. Dalam pelajaran kepemimpinan Kristen, Sam Soukotta berkata: "Buatlah kesalahan sebanyak mungkin, asal jangan

\footnotetext{
${ }^{1}$ L. Thomas Holdcroft, Kitab-kitab Sejarah (Malang: Penerbit Gandum Mas, 1996), 4.
} 
kesalahan yang sama"2 Ini memiliki pengertian, bahwa setiap orang akan belajar mengambil keputusan-keputusan. Sekalipun keputusan yang diambil bisa salah akan tetapi keputusan tersebut menjadikan orang itu belajar dari pengalaman, sehingga akan ada hikmat yang akan diperoleh pada setiap pengambilan keputusan.

Ketika Musa menjadi pemimpin Israel, Tuhan sudah mempersiapkan pengganti. Pengganti Musa bukanlah orang yang sekedar memiliki kecakapan dibidang pengetahuan atau kemampuan dalam memimpin. Tuhan mempersiapkan pengganti Musa, dengan seseorang yang memiliki kepribadian yang baik dan berkualitas. Dalam kemahatahuan Allah, Ia telah memilih seorang pemimpin yang akan memimpin bangsa Israel memasuki tanah perjanjian. Allah telah memilih seorang yang sudah dipersiapkan untuk memimpin bangsa yang terkenal dengan ketegarantengkuknya, bangsa yang suka protes dan mengeluh, bangsa yang sering membelakangi Allah. Oleh sebab itu Allah memilih seorang pemimpin yang berkualitas ${ }^{3}$. Dan Allah berkenan menemukan Yosua sebagai pengganti kepemimpinan dari Musa.

\section{Pengertian Kepemimpinan yang berkualitas}

Pontas Pardede mengatakan bahwa kepemimpinan pada hakikatnya adalah "pengaruh"4. Seorang pemimpin mempengaruhi orang lain agar dengan sukarela melakukan sesuatu. Lanjut dalam bukunya Kepemimpinan Rohani, Pontas Pardede mengutip pernyataan dari Presiden Amerika ke-33 Truman yang berkata bahwa seorang pemimpin memiliki kesanggupan untuk membuat orang lain melakukan sesuatu dengan sukarela, walaupun sebenarnya orang itu tidak ingin melakukannya, bahkan terkadang tidak menyukainya. ${ }^{5}$

Barna mendaftar beberapa pengertian tentang kepemimpinan dari tokoh-tokoh penting dalam Kekristenan. Sebab ia meyakini bahwa tidak ada definisi kepemimpinan yang bisa diterima secara universal. Beberapa kutipan tentang kepemimpinan yang dikutip oleh Barna sebagai berikut ${ }^{6}$ :

\footnotetext{
${ }^{2}$ Sam Soukotta, Diktat Kepemimpinan Kristen (Tawangmangu: Sekolah Tinggi Teologi Tawangmangu, 2002)

${ }^{3}$ Kualitas berarti tingkat baik buruknya sesuatu; atau bisa juga memiliki pengertian derajat/taraf (kepandaian; kecakapan, dsb)

${ }^{4}$ Pontas Pardede, tth. Kepemimpinan Rohani (Surakarta: Sekolah Tinggi Teologi

"Intheos"), 1.

${ }^{5}$ Ibid
} 


\begin{abstract}
Warren Bennis dan Buth Nanus
"Kepemimpinan adalah melakukan segala sesuatu dengan benar"

James McGregor Burn

"Kepemimpinan adalah bila seseorang dengan tujuan dan motivasi tertentu, mengerahkan, berlomba-lomba atau berkonflik dengan orang lain, dengan kelembagaan, dengan sumber-sumber politik, psikologi dan sumber-sumber lain untuk mengarahkan, mengajak dan memuaskan motif-motif para pengikutnya"

Vance Packard
\end{abstract}

"Kepemimpinan adalah membuat orang lain ingin melakukan sesuatu yang aku yakini harus dilakukan"

Tom Peters

"Kepemimpinan adalah menguasai lawan dan menguasai apa yang mereka pertahankan"

J. Oswald Sanders

"Kepemimpinan adalah pengaruh"

Garry Wills

"Kepemimpinan adalah mengarahkan orang lain menuju tujuan yang diperjuangkan bersama oleh pemimpin dan pengikut-pengikutnya"

Pengertian kepemimpinan di atas menjelaskan tentang fungsi seseorang dalam hubungannya dengan orang lain. Dalam hal ini orang yang disebut sebagai pemimpin adalah orang yang mampu menggerakkan orang lain.

Sementara hal yang berhubungan dengan kualitas pemimpin, mantan mentri Indonesia Rizal Ramli menyatakan, pemimpin berkualitas harus memenuhi tiga syarat utama, yaitu memiliki visi, karakter, dan kompetensi. ${ }^{7}$ Hal tersebut selaras dengan bagan yang dibuat oleh Brana yang menjelaskan tentang karakter dan kecakapan dari kepemimpinan seorang Kristen. Adapun bagan tersebut sebagai berikut ${ }^{8}$ :

\footnotetext{
${ }^{6}$ George Barna. 2002. Leaders On Leadership (Malang: Gandum Mas), 22-23.

${ }^{7} \mathrm{http} / / /$ www.republika.co.id/berita/pemilu/menuju-ri-1/14/02/23/n1fxjk-tigasyarat-pemimpin-berkualitas-ala-rizal-ramli (Diunduh tanggal 30 September 2014 pukul 22.00)

${ }^{8}$ Barna, Op.cit, 25-26
} 


\begin{tabular}{|c|c|}
\hline \multicolumn{2}{|c|}{ KARAKTER SEORANG PEMIMPIN SEPERTI KRISTUS } \\
\hline * Memiliki hati seorang hamba & * Dapat diajar \\
\hline Memiliki kedalaman rohani & * Jujur \\
\hline * Tahu membedakan & * Peka \\
\hline * Dikendalikan nilai-nilai & * Bijaksana \\
\hline * Mengampuni & Optimis \\
\hline * Loyal & * Bergairah \\
\hline * Berbelaskasihan & * Bersifat tenang \\
\hline * Tekun (tahan menderita) & * Adil \\
\hline * Bersemangat & * Gembira \\
\hline * Dapat dipercaya & * Sabar \\
\hline * Setia & Lemah lembut \\
\hline * Teguh hati (berani) & * Baik hati \\
\hline * Penguasaan diri & * Konsisten \\
\hline * Rendah hati & * Murah hati \\
\hline * Kasih & * Dapat dipercaya \\
\hline * Menghibur orang lain & * Kematangan rohani \\
\hline & Rela minta maaf \\
\hline
\end{tabular}

KECAKAPAN SEORANG PEMIMPIN KRISTEN

* Mampu berkomunkasi secara efektif

* Mampu mengenali, mengungkapkan dan menuangkan pandangan

* Mampu memotivasi orang

* Mampu melatih dan mengembangkan orang

* Mampu mengumpulkan informasi

* Mampu meyakinkan orang lain

* Mampu memprakarsai strategis

* Mampu menggunakan strategi berpikir

* Mampu memecahkan konflik

* Mampu mengembangkan berbagai sumber

* Mampu mendelegasikan wewenang dan tanggungjawab

* Mampu memperkuat komitmen

* Merayakan keberhasilan demi keberhasilan

* Mampu membuat keputusan

* Mampu membangun tim

* Menciptakan kerjasama dalam keserasian budaya

* Memelihara fokus dan prioritas

* Menegakkan pertanggungjawaban

* Mengenali berbagai kesempatan untuk mempengaruhi

* Menghubungkan segala sesuatu kembali pada rencana Tuhan dan prinsip-prinsip ketuhanan 
* Meneladani disiplin rohani

* Membina pemimpin-pemimpin kunci lainnya

Dengan kata lain yang dimaksudkan dengan pemimpin yang berkualitas adalah kepemimpinan yang dapat menggerakkan orang lain, dimana kepemimpinannya tersebut bisa diukur atau dinilai baik tidaknya (kualitasnya) oleh orang-orang yang dipimpinnya.

\section{Kepemimpinan Yosua}

Pemilihan Yosua sebagai pengganti Musa melewati rentang waktu yang cukup lama. 40 tahun Yosua harus dibawah kepemimpinan Musa, sebelum ia betul-betul ditahbiskan sebagai pemimpin. Hal ini menjadi alasan tersendiri bagi Musa ketika mempersiapkan Yosua sebagai pemimpin bangsa yang besar dalam kurung waktu yang lama. Sebab Musa mengetahui bahwa menjadi pemimpin bagi bangsa Israel tidaklah mudah. Dari dalam, siapapun yang akan memimpin bangsa Israel akan mendapatkan tantangan dari bangsa ini. Bangsa Israel pernah memberontak terhadap Musa dan Tuhan dengan membuat patung lembu emas untuk disembah. Sementara dari luar, pemimpin Israel harus membawa bangsa ini masuk ke tanah Kanaan, tanah yang pernah dijanjikan Tuhan untuk bangsa Israel. Namun untuk memasukinya, harus menghadapi orang-orang Kanaan asli yang memiliki perawakan yang besar dan tinggi seperti raksasa. Itulah sebabnya dari sekian orang yang ada dibangsa Israel, Musa mempersiapkan Yosua sebagai penggantinya, meskipun hal ini harus ditempuh Musa dalam waktu yang lama.

Proses Yosua sebagai pemimpin dimulai pada saat Israel menghadapi serangan dari bangsa Amalek (Kel 17:8-11). Yosua mendapat mandat dari Musa untuk memimpin perang dengan bangsa Amalek di Rafidim. Sementara Musa dibantu dengan Harun dan Hur berdoa untuk dapat memperoleh kemenangan tersebut. Kemudian dalam narasi Keluaran 17, diceritakan bahwa bangsa Israel memperoleh kemenangan atas bangsa Amalek. Selanjutnya Yosua juga terpilih sebagai pendamping Musa ketika Musa hendak naik ke gunung Allah untuk menerima hukum Allah (Kel 24:13). Ia juga terpilih dari suku Efraim untuk menjadi salah satu dari duabelas pengintai yang bertugas untuk mengamat-amati kondisi dan keadaan tanah Kanaan (Bil 13:1-16). 
Yosua 1:1-18, Yosua akhirnya dipilih Tuhan untuk menggantikan Musa, pemimpin yang berkharisma itu. Pemilihan Tuhan atas Yosua untuk menggantikan Musa, merupakan pemilihan Tuhan yang sudah dalam rencana-Nya. Rencana Allah, dalam menemukan pengganti pemimpin bangsa Israel akhirnya tergenapi dalam hidup Yosua.

Pemilihan Allah tidak pernah salah. Bahkan dalam ayat-ayat di atas, pemilihan Allah atas Yosua juga disertai dengan janji-janji Allah yang menjadikan kepemimpinan Yosua menjadi berhasil dikemudian hari. Yosua terpilih karena Yosua memiliki kualitas hidup yang baik. Bilangan 27:18, Tuhan menyuruh meletakkan tangan Musa kepada Yosua sebagai penggantinya, dengan alasan karena Yosua penuh dengan roh. "Seorang yang penuh dengan roh", kata roh di dalam bahasa Ibrani tidak mempunyai kata sandang. Sekalipun yang terutama dimaksudkan di sini adalah kemampuan alamiah yang dimiliki oleh Yosua, ia juga menerima urapan kuasa ilahi. Alkitab mengatakan bahwa Yosua "penuh dengan roh kebijaksanaan sebab Musa telah meletakkan tangannya ke atasnya" (Ul. 34:9). ${ }^{9}$ Kualitas kepemimpinannya juga terlihat pada saat Yosua dan Kaleb memberikan laporan tentang keadaan tanah Kanaan yang berbanding terbalik dengan sepuluh orang lainnya. Yosua dan Kaleb melihat fakta dengan iman kepada Allah, sementara sepuluh orang lainnya melihat fakta dengan keberadaan diri mereka sendiri tanpa menaruh rasa percaya kepada Allah.

\section{Kualitas Kepemimpinan Yosua}

Kualitas kepemimpinan Yosua dapat dipelajari dalam Alkitab. Adapun beberapa kualitas kepemimpinan Yosua yang bisa dipelajari dan kemudian menjadi implikasi bagi pemimpin masa kini adalah sebagai berikut:

Pertama: Yosua adalah pemimpin yang rendah hati

Kerendahan hati seseorang tidak diukur dari penampilan atau gaya seseorang. Di dalam banyak budaya, sikap merendahkan tubuh dianggap sebagai kerendahan hati. Sesungguhnya kerendahan hati bukanlah sikap tubuh melainkan sikap hati, yang tidak mementingkan diri, malah mengedepankan kepentingan orang lain. Orang yang rendah hati memprioritaskan kepentingan orang lain dari pada kepentingan dirinya sendiri.

\footnotetext{
${ }^{9}$ http://alkitab.sabda.org/commentary.php?book=4\&chapter=27\&verse $=18$
} (Diunduh tanggal 1 Oktober 2014) 
Yosua disebut sebagai pemimpin yang rendah hati, karena sebelum menggantikan Musa, Yosua menjadi pelayannya Musa selama 40 tahun. Pelayan dalam bahasa Ibrani עָּבָ - 'AVAD, kata ini memiliki pengertian seseorang yang melayani di ibadah atau yang berhubungan dengan ritual keagamaan. ${ }^{10}$ Yosua menjadi abdi Musa dan sekaligus terlibat dalam pelayanan di bidang keagamaan. Hal ini tercatat dalam Keluaran 33, dimana Musa mendirikan kemah pertemuan, yang dipakai untuk berbicara dengan Tuhan. Dalam ayat 11, Yosua tidak meninggalkan kemah pertemuan. Ia tetap di sana sebagai pelayan Musa sekaligus menjadi pelayan Tuhan.

Kata abdi yang diambil dari bahasa Ibrani שרת (shârath) menggambarkan keberadaan seseorang yang terlibat dalam pelayanan. ${ }^{11}$ Pelayanan Yosua selama 40 tahun kepada Musa menjadi bagian proses dari kepemimpinan Yosua.

Dalam Perjanjian Baru, Yesus pernah berkata kepada murid-muridNya: "Tetapi kamu tidaklah demikian, melainkan yang terbesar di antara kamu hendaklah menjadi sebagai yang paling muda dan pemimpin sebagai pelayan" (Luk 22:26) . Salah satu kualitas yang dimiliki oleh seorang pemimpin adalah pemimpin sebagai pelayan. Demikianlah Yosua, ia seorang pemimpin yang memiliki kualitas kepimimpinan yang rendah hati.

Kedua: Yosua adalah pemimpin yang percaya penuh kepada Allah

Keberhasilan Yosua menjadi pemimpin disebabkan ia memiliki kepercayaan penuh kepada Allah. Penyertaan Allah dalam Yosua menjadi landasan kuat dalam hidupnya, hal ini terlihat pada saat dia mendampingi Musa. Ketika Musa menjadi pemimpin bagi sekian juta umat Israel, Musa meminta agar Tuhan berjalan di depan bangsa itu, bahkan Musa tidak mau memimpin bangsa Israel, jika Tuhan tidak menyertai bangsa Israel. Hal ini kemudian diikuti oleh Yosua, pada waktu Yosua diangkat menjadi pemimpin menggantikan Musa. Kepercayaan kepada Allah dibangun oleh Yosua dengan membangun hubungan pribadi dengan Allahnya sejak di usia muda. Yosua sering berada di Bait Allah menemani Musa berbicara dengan Allah. Yosua bahkan tidak mau meninggalkan Bait Allah cepat-cepat, sekalipun Musa sudah selesai berbicara dengan Allah. Dia sangat menikmati berada di Bait Allah. Kebiasaan inilah yang kemudian menjadikan Yosua memiliki kepercayaan penuh kepada Allah.

${ }^{10} \mathrm{http} / / /$ www.sarapanpagi.org/layan-pelayanan-vt1197.html (Diunduh tanggal 1

${ }^{11}$ E-Sword: Dictionary - Strong, Software Alkitab. 
Ketiga: Yosua adalah pemimpin yang suka akan Firman Tuhan

"Janganlah engkau lupa memperkatakan kitab Taurat ini, tetapi renungkanlah itu siang dan malam, supaya engkau bertindak hati-hati sesuai dengan segala yang tertulis di dalamnya, sebab dengan demikian perjalananmu akan berhasil dan engkau akan beruntung". ${ }^{12}$ Nasehat yang diberikan Tuhan secara pribadi kepada Yosua salah satunya berisi pentingnya memperkatakan dan merenungkan Firman Allah, dimana hal ini akan menentukan keberhasilan dari kepemimpinan Yosua. Firman Allah menjadi ukuran keberhasilan dari kehidupan Yosua. Dalam Ulangan 28, berbicara tentang berkat dan kutuk. "Jika engkau baik-baik mendengarkan suara TUHAN Allahmu, dan melakukannya dengan setia segala perintahNya yang kusampaikan kepadamu pada hari ini, maka TUHAN, Allahmu, akan mengangkat engkau di atas segala bangsa di bumi”. Yosua bersama bangsa Israel mendengarkan Firman ini, ketika Firman ini diucapkan oleh Musa kepada bangsa Israel. Yosua taat akan perintah Tuhan yang disampaikan oleh Musa. Lanjut, ketika Yosua diangkat oleh Tuhan untuk menggantikan Musa, perintah untuk hidup dalam Firman Allah diulang kembali oleh Tuhan. Dalam Yosua 1:8 "Janganlah engkau lupa memperkatakan kitab Taurat ini, tetapi renungkanlah itu siang dan malam, supaya engkau bertindak hati-hati sesuai dengan segala yang tertulis di dalamnya, sebab dengan demikian perjalananmu akan berhasil dan engkau akan beruntung". Tuhan menjanjikan suatu keberhasilan kepada Yosua, apabila ia mau mendengar dan melakukan Taurat (Firman) Tuhan. Hal inilah yang kemudian menjadikan suatu pola hidup dalam kehidupan Yosua, yaitu pola membaca, merenungkan dan melakukan Firman Tuhan. Sampai akhir hidup Yosua, keberhasilan-keberhasilan selalu ia raih, saat ia mempertahankan pola membaca dan merenungkan Firman Tuhan.

Keempat: Yosua adalah pemimpin yang suka berdoa

Doa adalah komunikasi seseorang dengan Tuhan. Seseorang berdoa kepada Tuhan, karena ia menyadari bahwa ia membutuhkan Tuhan. Yosua adalah seorang pemimpin yang suka berdoa. Yosua menyenangi doa, ketika masih berada di dalam didikan kelurganya di Mesir. Ketika keluar dari Mesir, Yosua sering menemani Musa untuk berdoa di kemah Suci. Kehidupan doa Yosua yang terus dilakukan dari sejak dia muda sampai ia 
menggantikan kepemimpinannya Musa, menjadikan Yosua hidup dalam keberhasilan.

Dalam singkatan bahasa Inggris PUSH (Pray Until Something Happen: Berdoalah sampai sesuatu terjadi), ternyata banyak hal yang bisa terjadi oleh sebab doa. Yosua berdoa kepada Tuhan saat akan melewati sungai Yordan (Yos 3:10-17), dan pada saat Yosua berdoa, Tuhan menjawab doa Yosua dan sungai Yordan dibuat berhenti mengalir dan tanah menjadi kering, agar bangsa Israel bisa melewati sungai Yordan Tersebut. Yosua berdoa kepada Tuhan waktu ia dan bangsa Israel hendak melawan Yerikho (Yos 6:1- 27), Tuhan memberikan petunjuk kepada Yosua, dan Tuhan menjawab doa Yosua dengan memberikannya kemenangan yang gemilang. Bahkan kabar akan kemenangan ini tersebar sampai seluruh negeri Kanaan (Yos 6:27). Yosua menyadari bahwa keberhasilannya memimpin bangsa Israel, bukan semata-mata dari kemampuan yang ia miliki atau kepandaian yang ia punya, tetapi semua keberhasilannya bergantung kepada Allah lewat doa-doa yang ia sampaikan kepada Allah.

Kelima: Yosua adalah pemimpin yang penuh dengan Roh

Kisah kedua belas pengintai dalam kitab Bilangan 13, dideskripsikan bahwa ada respon yang berbeda antara 10 pengintai dan Yosua serta Kaleb. 10 pengintai berkata bahwa negeri itu memang berlimpah susu dan madu, hanya bangsa yang diam di negeri itu kuat-kuat dan kota-kotanya berkubu dan sangat besar. Mereka juga melihat di sana ada orang Enak yang berasal dari orang-orang raksasa, dan mereka melihat diri mereka seperti belalang. Yosua dan Kaleb pun sebenarnya melihat hal yang sama seperti yang dilihat oleh 10 pengintai, hanya saja respon Kaleb dan Yosua berbeda dengan mereka. Kaleb terlebih dahulu memberikan respon dengan menenangkan bangsa itu dengan berkata: "Tidak! Kita akan maju dan menduduki negeri itu, sebab kita pasti mengalahkannya!" (Yos 13:30). Lalu kemudian Yosua juga meyakinkan bangsa itu, bahwa Tuhan akan menyertai mereka dan mampu mengalahkan bangsa itu, asalkan mereka tidak memberontak kepada Tuhan. (Yos 14:6-9). Respon yang dimiliki oleh Yosua dan Kaleb disebabkan oleh karena mereka memiliki roh yang berbeda dengan pengintai yang lain (Yos 14:24).

Yosua adalah pemimpin yang penuh dengan roh, hal ini disebabkan karena Yosua mendapatkan pelayanan penumpangan tangan dari Musa kepada Yosua. Kehidupan yang penuh dengan Roh Allah, memberikan kemampuan kepada Yosua untuk ia tetap hidup di dalam kehendak Tuhan. 
Hidup dalam kepenuhan Roh sangatlah penting, bahkan hal ini sampai terulang dalam nasehat Paulus kepada jemaat di Galatia, dimana Paulus menasehatkan jemaat agar hidup oleh roh dan bukan menuruti keinginan daging.

Keenam: Yosua adalah pemimpin yang memprioritaskan Tuhan.

Semasa Yosua hidup bersama-sama dengan bangsa Israel setelah mereka keluar dari perbudakan Mesir, Yosua banyak sekali mendengarkan Firman Tuhan. Salah satu yang ia dengar di dalam Ulangan 6:5 "Kasihilah TUHAN, Allahmu, dengan segenap hatimu dan dengan segenap jiwamu dan dengan segenap kekuatanmu." Ini menjadi hukum yang terutama di dalam kehidupan bangsa Israel. Mereka diwajibkan memiliki prioritas terhadap Tuhan. Dengan memprioritaskan Tuhan, Tuhan akan berjanji memberikan keberhasilan dalam melakukan apa saja yang sesuai dengan kehendak-Nya.

Yosua adalah pemimpin yang memprioritaskan Tuhan dalam hidupnya. Bahkan saat Yosua menyadari bahwa usianya sudah lanjut, ia berpesan kepada bangsa Israel agar tetap memprioritaskan Tuhan dalam kehidupan mereka. Dalam pidatonya kepada bangsa Israel Yosua berkata demikian: "Tetapi jika kamu anggap tidak baik untuk beribadah kepada TUHAN, pilihlah pada hari ini kepada siapa kamu akan beribadah; allah yang kepadanya nenek moyangmu beribadah di seberang sungai Efrat, atau allah orang Amori yang negerinya kamu diami ini. Tetapi aku dan seisi rumahku, kami akan beribadah kepada Tuhan!". Yosua telah mengambil ketetapan untuk memprioritaskan Tuhan dalam hidupnya. Bahkan sampai maut menjemputnya, ia tetap dalam posisi memprioritaskan Tuhan dalam hidupnya.

\section{Kesimpulan}

Kepemimpinan bukanlah ada begitu saja. Kepemimpinan muncul oleh adanya proses dalam diri seseorang, sampai akhirnya orang tersebut diangkat menjadi pemimpin. Keberadaan seorang pemimpin, bukan ada oleh karena ada sebuah kebutuhan saja. Tetapi lebih dari itu, seorang pemimpin dibutuhkan juga kualitas dalam kepemimpinannya. Salah satu karakteristik dalam kepemimpinan yang bisa dipelajari dalam Alkitab adalah kepemimpiinan Yosua. Yosua menjadi pemimpin oleh karena proses yang panjang. Dan Yosua menjadi pemimpin yang memiliki kualitas kepemimpinan yang baik. Beberapa kualitas kepemimpinan Yosua: dia seorang pemimpin yang rendah hati, dia seorang pemimpin yang percaya 
penuh kepada Allah, dia seorang pemimpin yang menyukai Firman Tuhan, dia seorang pemimpin yang suka berdoa, dia seorang pemimpin yang penuh dengan roh, dan dia seorang pemimpin yang memprioritaskan Tuhan.

\section{Kepustakaan}

Prince, Derek. 2005. Foundations for Righteous Living, Jakarta: Derek Prince Ministries Indonesia.

Pardede, Pontas. tth. Kepemimpinan Rohani. Surakarta: Sekolah Tinggi Teologi Intheos.

Rush, Myron. 2002. Manajemen Menurut Pandangan Alkitab. Malang: Penerbit Gandum Mas.

Somarsono, Hariono. 2003. Tim dan Teamwork Plus. Bandung: Lembaga Literatur Baptis.

Barna, George. 2002. Leaders on Leadership. Malang: Penerbit Gandum Mas.

Soukotta, Sam. tth. Diktat Kepemimpinan Kristen, Tawangmangu: STT Tawangmangu. 